DOI 10.37882/2500-3682.2020.11.10

\title{
СОВРЕМЕННЫЙ ПСИХОЛОГИЧЕСКИЙ ИНСТРУМЕНТАРИЙ ОЦЕНКИ ЛИЧНОСТНО-ПРОФЕССИОНАЛЬНОГО РАЗВИТИЯ
}

\section{MODERN PSYCHOLOGICAL TOOLS FOR ASSESSING PERSONAL AND PROFESSIONAL DEVELOPMENT}

\section{N. Ivanova}

Summary: Personal and professional development reflects the level of expression of personal qualities associated with professional activity and its success, and also shows qualitative changes in the personality over a certain period of time associated with professional success. Psychological tools - a set of technologies and methods of the psychologist's activity. Tools should be considered as a means of professional activity both from the point of view of requirements for selection and configuration, and from the side of theoretical concepts and correctional and diagnostic technologies. There are a large number of methods that study personal and professional development. in this article, the author cites several of the most modern ones, gives their characteristics and provides psychological tools for each method.

Keywords: psychological tools, personal and professional development, non-specific tools, specific tools.

\author{
Иванова Наталья Георгиевна \\ К.nсх.н., доцент, ФГБОУ ВО «Красноярский \\ государственный педагогический университет \\ им. В.П. Астафьевва» \\ natalya-i15@mail.ru
}

Аннотация: Личностно-профессиональное развитие отражает уровень выраженности качеств личности, связанных с профессиональной деятельностью и ее успешностью, а также показывает качественные изменения личности за определенный промежуток времени, связанных с профессиональной успешностью. Психологический инструментарий - совокупность технологий и методов деятельности психолога. Рассматривать инструментарий как средство профессиональной деятельности стоит как с позиции требований, относительно подбора и комплектации, так и со стороны теоретических представлений и коррекционно-диагностических технологий. Методик, изучающих личностно-профессиональное развитие большое количество, в данной статье автор приводит несколько наиболее современных, дает их характеристику и приводит психологический инструментарий на каждую методику.

Ключевые слова: психологический инструментарий, личностно-профессиональное развитие, неспецифический инструментарий, специфический инструментарий.
Л ичностно-профессиональное развитие отражает уровень выраженности качеств личности, связанных с профессиональной деятельностью и ее успешностью, а также показывает качественные изменения личности за определенный промежуток времени, связанных с профессиональной успешностью. Такое личностное развитие можно отслеживать с помощью процедуры мониторинга - процедуры систематического сопоставления измерения уровня выраженности профессиональных и личностных качеств. Мониторинг позволяет оценить личностно-профессиональное развитие через динамику его изменений.

К психологическим показателям эффективности А.К.

Таблица 1.

Пример классификации психологического инструментария.

\begin{tabular}{|c|c|c|c|}
\hline \multicolumn{2}{|c|}{ Неспецифический инструментарий } & \multicolumn{2}{|c|}{ Специфический инструментарий } \\
\hline Вспомогательные средства & Технический материал & $\begin{array}{l}\text { Стимульный материал (включен } \\
\text { инструментарий, необходимый для } \\
\text { нескольких диагностик, данный } \\
\text { перечень не является исчерпыва- } \\
\text { ющим) }\end{array}$ & Интерпретационные средства \\
\hline $\begin{array}{l}\text { Атрибуты сюжетно-ролевых игр; } \\
\text { Мячи, спортивный инвентарь; } \\
\text { СD-диски, флеш-носители, на которых } \\
\text { записаны воспроизведение вербального } \\
\text { и музыкального сопровождения диа- } \\
\text { гностической деятельности; } \\
\text { Наборы для моделирования и конструи- } \\
\text { рования }\end{array}$ & $\begin{array}{l}\text { Фломастеры, краски, цветные } \\
\text { карандаши, альбомные листы } \\
\text { различного формата, ножницы, } \\
\text { клей, цветная бумага и т.д. }\end{array}$ & $\begin{array}{l}\text { Геометрические фигуры, пирамид- } \\
\text { ки, сюжетные картинки, печатный } \\
\text { материал, состоящий из схем, } \\
\text { образных изображений, матриц, } \\
\text { наборы карточек, различные } \\
\text { плоскостные фигуры и т.д. }\end{array}$ & $\begin{array}{l}\text { Компьютерные программы по } \\
\text { сравнению, интерпретации и соот- } \\
\text { несению полученных данных в ходе } \\
\text { психологического взаимодействия; } \\
\text { Сетки переводов количественных в } \\
\text { качественные показатели; } \\
\text { Графики, таблицы профили; }\end{array}$ \\
\hline
\end{tabular}


Маркова [5] относила участие разных сторон психики человека в процессе труда, мотивационную зрелость, напряженность психических процессов и функций, достигнутый человеком социальный статус, отработанность исполнительных действий, операций, а также зрелость волевых компонентов, удовлетворённость от результатов труда и заинтересованность человека в нем, работоспособность, свободный выбор средств, форм, целей и результата труда, сопоставление цены результата и затраченных личностных ресурсов. Психологический подход тем самым позволяет оценивать потенциал сотрудников и получить наиболее точную оценку.

В развернутом понимании психологическим инструментарием принято считать совокупность технологий и методов деятельности психолога. Рассматривать инструментарий как средство профессиональной деятельности стоит как с позиции требований, относительно подбора и комплектации, так и со стороны теоретических представлений и коррекционно-диагностических технологий. Какой же должен быть психологический инстру- ментарий? В первую очередь он должен соответствовать стандарту, то есть заложенному авторов оригиналу коррекционно-диагностического средства. Это требование можно отнести ко всему интерпретационному и стимульному материалу. Следующее требование - соответствующая комплектация инструментария интерпретационного и стимульного материалов. Не рекомендуется использовать диагностические средства при отсутствии какого-либо материала, заложенного в оригинальной методике, например, при отсутствии шкал для перевода баллов в стандартизированных методиках становится невозможна правильная интерпретация данных диагностики. В некоторых случаях психологический инструментарий может быть признан монофункциональным, то есть нельзя применять интерпретационный или стимульный материал одного средства взамен другого, чаще всего инструментарий не взаимозаменяем и отчасти специфичен.

В таблице 1 приведен пример классификации психологического инструментария.

\section{1. Методики для изучения работоспособности}

\section{Методика, описание} гностика функционального состояния ЦНС
Вариационная хронорефлексометрия - прогноз работоспособности и диа-

Психологический инструментарий

Флеш-накопитель с компьютерной программой, рассчитанной примерно на 5 минут работы, возможность многократного применения, сюда входит сама программа тестирования, обработки, интерпретации результатов и их хранение;

Методическое руководство «Экспресс-диагностика работоспособности и функционального состояния человека. Рекомендации по допуску к работе», М. П. Мор03

Тест Ландольта, входит в группу корректурных тестов, позволяет проанализировать общую работоспособность и ее составляющие, такие как скорость, продуктивность, выносливость, безошибочность и надежность

Тест Тулуз-Пьерона, представляющих из себя невербальный тест - диагностику минимальных мозговых функций. Изучает свойства внимания (переключаемость, концентрация, стрессоустойчивость) и оценивает надежность и точность переработки информации, личностные характеристики работоспособности, волевую регуляцию и динамику по времени работоспособности

Цветовой тест - модификации известной методики М. Люшера, позволяет прогнозировать стрессоустойчивость и диагностировать эмоциональное состояние
Бланки фиксации результатов;

Бланки ответов;

Секундомер;

Методическое руководство «Тест Ландольта. Диагностика работоспособности», В. Н. Сысоев;

Ключи для ручной обработки результатов;

Флеш-накопитель с программой интерпретации, обработки и хранения результатов

Бланки фиксации результатов;

Бланки ответов;

Секундомер;

Методическое руководство «Тест Тулуз-Пьерона. Оптимизация обучения и развития детей с ММД», Л. А. Ясюкова;

Ключи для ручной обработки результатов;

Флеш-накопитель с бланками фиксации результатов

Приложение к методическому руководству «Интерпретационные таблицы»; 2 набора цветных карточек;

Флеш-накопитель с программой интерпретации, обработки и хранения результатов;

Бланки фиксации результатов;

Методическое руководство «Цветовой тест отношений», А. М. Эткинд;

Методическое руководство «Цветовой тест диагностики нервно-психических состояний», В. И. Тимофеев, Ю. И. Филимоненко 


\section{2. Методики для изучения особенностей личности}

Методика, описание

Методика «АКорД», позволяет спрогнозировать уровень антикоррупционной устойчивости личности

Психологический инструментарий

Флеш-накопитель с программой тестирования, интерпретации, обработки и хранения результатов;

Стимульные бланки к шкалам: саморегуляция и самодостаточность;

Бланки фиксации результатов к шкалам: саморегуляция, субъективная семантика, самодостаточность;

Ключи для ручной обработки результатов шкал: самодостаточность и саморегуляция;

Методическое руководство «Компьютеризированная система антикоррупционной диагностики «АКорД», О. В. Ванновская

16-факторный личностный опросник Кеттелла, служит для диагностики взрослых в различных ситуациях, в первую очередь для оценки нормальной личности, позволяет описать личностную структуру, найти компенсаторные механизмы для психического здоровья и обозначить внутриличностные проблемы

Фрустрационный тест Розенцвейга, предназначен для прогнозирования поведения в межличностном взаимодействии и реагировании поведения в межличностном взаимодействии

Личностный опросник MMPI - диагностическая методика для углубленной диагностики психологических особенностей личности взрослых людей
Опросники: 16PF (форма А и В); HSPQ, (PQ для мальчиков и девочек;

Методическое руководство «Факторный личностный опросник Кеттелла», А. А. Рукавишников, М. В. Соколова;

Ключи для ручной обработки: $16 \mathrm{PF}, \mathrm{HSPQ}, \mathrm{CPQ}$

Бланки ответов и фиксации: $16 \mathrm{PF}, \mathrm{HSPQ}, \mathrm{CPQ}$

Флеш-накопитель с программой тестирования, интерпретации, обработки и хранения результатов

\section{Атлас карточек;}

Бланки ответов;

Флеш-накопитель с программой обработки и хранения результатов; Методическое руководство «Фрустрационный тест Розенцвейга. Диагностика реакций в ситуациях конфликта», Л. А. Ясюкова;

Бланки фиксации результатов

Опросник (женский и мужской вариант);

Бланки ответов;

Ключи для ручной обработки результатов;

Флеш-накопитель с программой тестирования, интерпретации, обработки и хранения результатов;

Методическое руководство «Личностный опросник MMPI», И. Л. Соломин
Методы оценки личностно-профессионального развития в основном относятся к эмпирическим, основываясь на распространении функционального опыта и успешного отраслевого, а также использования в принятии решений прецедентного опыта. Эмпирические методы делятся на качественные и количественные. Количественные методы можно описать как массовые и формализованные. Формализм заключается в строгой направленности на изучение ранее заданных переменных и их количественном измерении, высокий его уровень объясняется дальнейшей статистической обработкой. Наверное, самым распространенным методом этой группы является анкетирование, в ходе которого испытуемому предлагается письменно ответить на вопросы опросного листа (анкеты). Инструментарий данного метода наиболее простой и включает в себя сам опросный лист и интерпретационные средства. Простота использования данного метода дает возможность применять анкетирование как отдельно, так и в комплексе с другими методами для оценки личностно-психологического развития. Вопросы анкетирования бывают открытые (свободный ответ) и закрытые (выбор ответа из несколь- ких предложенных утверждений). Одним из видов анкетирования, применяемым для изучения личностно-профессиональных качеств работника служит личностный опросник, представляющий из себя списки вопросов, на которые испытуемый отвечает количественно.

Методик, изучающих личностно-профессиональное развитие большое количество, в данной статье приведем лишь некоторые из них, разделив их по группам.

Для оценки личностно-профессиональных качеств психологи стремятся чаще всего использовать не одиночные методики, а комплексные системы диагностики с несколькими методиками, дабы исключить ошибки, которые могут возникнуть в процессе анализа. Важно не просто собрать несколько методик вместе, а подобрать такие методики и соответствующий им психологический инструментарий, который будет максимально подходить под конкретные условия, в которых существуют испытуемые. Большое значение кроме всего прочего имеет знания специалиста, проводящего диагностику, и его компетенция в области психологии. 


\section{ЛИТЕРАТУРА}

1. Акимова М.К. Психологическая диагностика / под ред. М.К. Акимовой. — СПб.: Питер, 2005.

2. Гуревич К.М. Психологическая диагностика: учебное пособие / К.М. Гуревич. — М., 1997.

3. Лнастази А. Психологическое тестирование / А. Анастази, С. Урбина. - СПб.: Питер, 2001.

4. Мамай Л.А. Особенности психологической оценки эффективности работы специалистов: обзор подхода, методов и методик / Л.А. Мамай. — Текст: непосредственный // Молодой ученый. — 2015. — № 18 (98). — С. 336-341.

5. Маркова А.К. Психология профессионализма. - М., 1996.- 308 с.

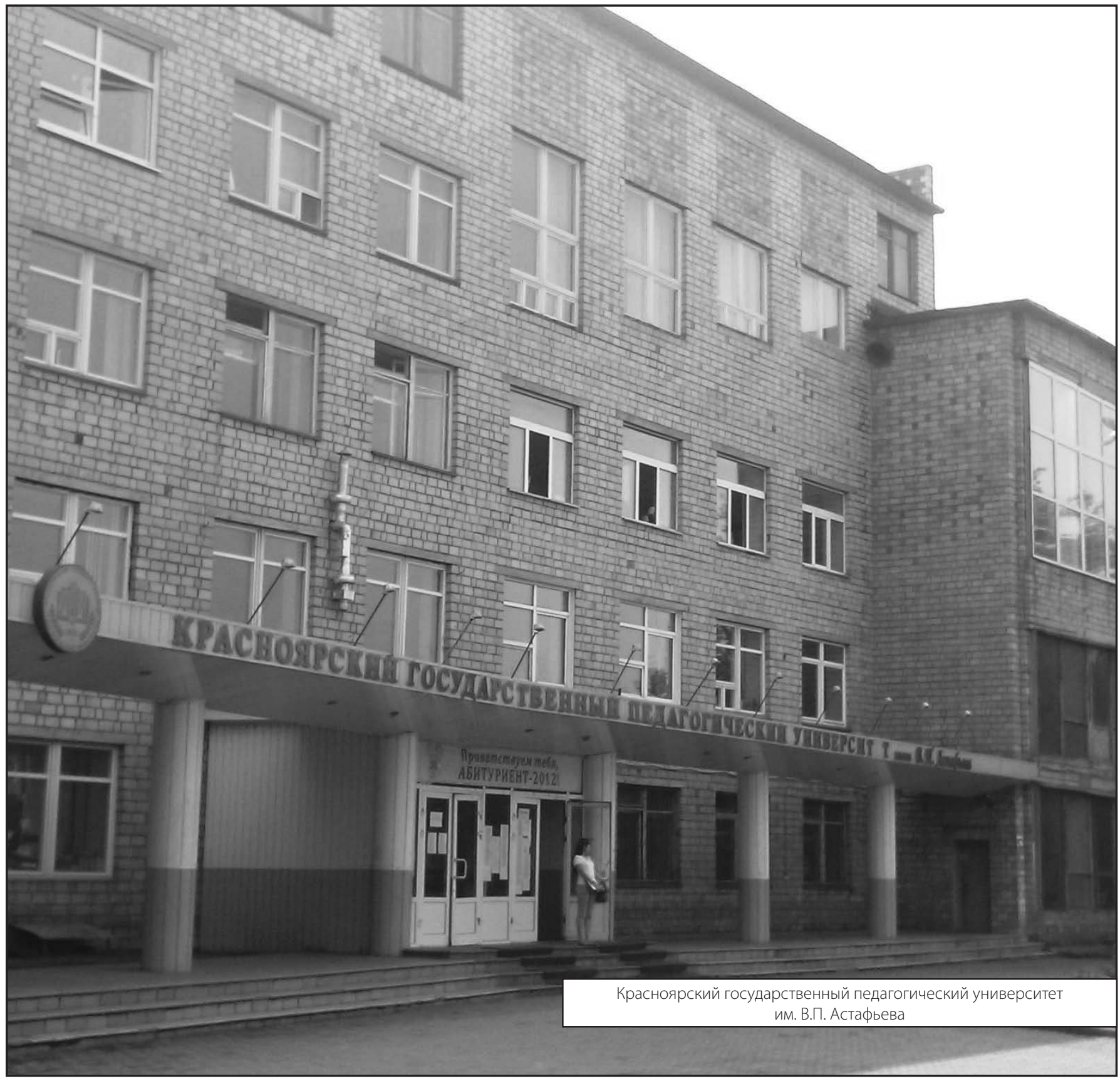

